care, from $\$ 55.52$ to $\$ 41.02$ PPPM.

With regard to the intervention itself, the coverage limit on migraine-abortive drugs was applied specifically and solely to triptans ( 5 were on the market at the time) and DHE nasal spray, and there was no prior-authorization (PA) or medical exception process. The coverage limit was applied as a drug-specific milligram quantity per month of therapy (30 days). A coverage limit applied to a class of drugs (e.g., triptans) rather than to individual triptan drugs would presumably result in a larger decline in drug-class costs as well as better address the clinical outcomes reportedly sought by the authors. In the 18-month period after implementation of the drug-specific milligram limit per month (30 days), the PPPM cost of triptans and DHE nasal spray declined from $75 \%$ to $67 \%$ of total migraine-related drug costs, \$29.18 PPPM and \$20.78 PPPM, respectively.

Stacy, Shaw, Arledge, and Howell-Smith estimated that a PA requirement for cyclooxygenase-2 (COX-2) specific inhibitors was associated with utilization and cost reduction of COX-2 drugs of $\$ 0.31$ PMPM in 2000 dollars or \$0.24 PMPM after subtraction of the administrative costs of the call center, producing aggregate savings of $\$ 10$ million per year in their MCO of 3.3 million members with a pharmacy benefit. ${ }^{10}$ The authors predicted from a cost-effectiveness model that the cost per success, defined as no serious gastrointestinal (GI) event (i.e., upper GI ulcers, bleeding, or perforation), was $\$ 278$ with a PA requirement for COX-2 drugs versus $\$ 422$ per success without the PA requirement. This difference translates into \$13.6 million in additional cost per year in 2000 dollars or about $\$ 0.35$ PMPM if the PA requirement for COX-2 drugs was removed from the pharmacy benefit.

Current research published elsewhere found that COX-2 drugs become cost effective compared to the nonselective nonsteroidal anti-inflammatory drug naproxen (Naprosyn, Aleve) only if the estimated average cost of $\$ 2.66$ per COX-2 tablet is reduced by $90 \% .{ }^{11}$ Using a COX-2 drug instead of a nonselective NSAID in average-risk patients had an incremental cost of $\$ 275,809$ per year to gain 1 additional quality-adjusted life-year (QALY), which dropped to $\$ 55,803$ for each QALY gained when the analysis was limited to the subset of patients with a history of bleeding ulcers. Readers might note that both studies recognize a 50\% relative risk reduction for serious GI event for COX-2 drugs compared to nonselective NSAIDs in treating chronic arthritis pain, and both studies employed a factor of $1 \%$ for the absolute risk reduction in serious GI events for COX-2 drugs versus NSAIDs. Collectively, the 2 studies suggest that a PA requirement for COX-2 drugs may be appropriate and cost effective when measured by clinical and cost outcomes.

\section{Pressure on Pharmacy Benefit Managers for Disclosure and Demonstration of Value- Rebates and Drug Benefit Cost Savings}

The Bush administration issued a press release in late April
2003 warning pharmaceutical manufacturers and pharmacy benefit managers that payments to health plans or PBMs for increasing the market share of a drug could be illegal under the antikickback statute of federal law. The guidance provided by Janet Rehnquist, inspector general of the U.S. Department of Health and Human Services, defined "legitimate discounts" as a reduction in the price of a prescription drug "properly disclosed and accurately reported."12 The Office of the Inspector General (OIG) advised drug manufacturers and PBMs to disclose their financial arrangements to payers, including employer-sponsored health plans, in order to escape prosecution under the antikickback laws. The OIG guidance also warned drug manufacturers that (a) research and education grants must be divorced from marketing and (b) "to the extent the manufacturer has any influence over the substance of an educational program or the presenter, there is a risk that the program may be used for inappropriate marketing purposes." ${ }^{13}$

PBMs have also come under pressure to demonstrate value in promised drug benefit cost savings. A survey of 543 U.S. employers, representing about 6 million benefits-eligible employees, found $42 \%$ of the employers felt that involvement by PBMs contributed to higher drug benefit costs versus 28\% who said that PBMs decrease overall drug benefit costs. There was also interest in making changes in drug benefit management in the future, including (a) mandatory disclosure of rebate income received by PBMs (40\%), (b) mandatory refills at mailorder for maintenance drugs (28\%), and (c) pairing physician networks with pharmacy networks to prescribe lower-cost alternatives (22\%). ${ }^{14}$ Federal legislation to restrict patent extensions on brand-name drugs was favored by $75 \%$ of employers.

The requests for more disclosure of financial arrangements are not new but became more vociferous in 2003. A forum on PBM practices in late 1998 suggested full disclosure as a standard of practice in the PBM industry, including full disclosure of all manufacturer relationships. ${ }^{15}$ For example, there was a charge that some PBMs are being paid "to keep drugs off the Maximum Allowable Cost list [by some manufacturers] at the expense of the customer." The forum on PBM practices also recommended the ability to audit the actual reimbursement rates and amounts paid by PBMs to participating pharmacies, with no margin retained by PBMs. One PBM officer stated at a forum in mid-1999 that "repricing" by PBMs (in which the plan sponsor is billed a higher amount than what is actually paid to the pharmacy provider) was probably only illegal when the practice is not disclosed to Employee Retirement Income Security Act (ERISA) clients but may be illegal for (non-ERISA) government agencies and municipalities (non-ERISA plans) that do not fall under the ERISA regulations. ${ }^{16}$

Lawsuits filed by plan sponsors against PBMs for not disclosing the practice of repricing date back to at least as early as 1998. ${ }^{17}$ A Wall Street Journal investigation in March 2003 revealed that a PBM had charged a Westport, Connecticut, 
employer $\$ 215$ for a prescription claim for 90 tablets of ranitidine (generic Zantac) for which the PBM had paid the community pharmacy $\$ 15$, a $\$ 200$ gross margin for the PBM on a single prescription. The PBM reported that such practices helped to push its net income up 63\% in 2002, and this business practice of taking the "spread" between reimbursement paid to pharmacies and the amount billed to drug plan sponsors, including government employers, had replaced revenue otherwise available in administrative fees for claims processing and other services. ${ }^{18}$ Another PBM's senior officer told attendees at an investors' conference on January 8, 2002, that PBM margins and profits came from claims processing fees in 1995, but in 2001 and 2002, "We receive payments from pharmaceutical manufacturers that are not shared with our clients...in the form of administrative fees, what we call therapeutic class partnerships [and] intervention programs." ${ }^{19}$

PBM supporters include the U.S. General Accounting Office. In a report in January 2003, the GAO found that PBMs saved customers an average of $18 \%$ compared to what customer would pay in community pharmacies without third-party coverage administered through the PBMs and 27\% discount through mail-order pharmacy. ${ }^{20}$ The GAO found additional discounts negotiated with mail-order pharmacy resulted in lower out-of-pocket costs for drug plan members, reduced costs for drug plan sponsors, and "helped to lessen rising premiums." The GAO did acknowledge that community pharmacies were forced by PBMs to accept discounted reimbursements while performing additional administrative tasks. In addition to pricing, the GAO estimated that drug manufacturer rebates "reduced plans' annual spending on prescription drugs by 3\% to $9 \%$." No evidence of the value of rebates was presented in the GAO report in January 2003. The GAO report does include the following statement, with a footnote and references to U.S. Securities and Exchange Commission (SEC) filings, "Public financial information suggests that manufacturer payments are important sources of earnings. For example, in financial reports submitted to the SEC, 2 of the PBMs we reviewed stated that manufacturer rebates and fees were key to their profitability."21

The GAO report in January 2003 was not a resounding endorsement of the value of PBMs. In addition to the uncompensated workload pushed upon community pharmacists and difficulty in quantifying "rebate savings," the GAO examined other PBM "intervention techniques" such as drug utilization review (DUR), prior authorization (PA), generic substitution, and therapeutic interchange, and concluded that "their full impact on savings is not easily quantifiable." ${ }^{22}$ The GAO found that the 3 PBMs that it reviewed reported savings for individual intervention techniques ranging from less than 1\% to $9 \%$, but a footnote in the report states, "While plans reported savings from therapeutic interchange, concerns have been raised that in some cases, PBMs' relationships with manufacturers and retail pharmacies influence PBM interventions, such as substituting high- er-cost drugs when lower-cost therapeutic equivalent drugs are available. Medco Health Solutions and Advance PCS filings with the SEC indicated that the U.S. Department of Justice is undertaking an industrywide investigation to examine PBM relationships with pharmaceutical manufacturers and retail pharmacies and PBMs' programs related to drug formulary compliance, which includes rebates and other payments made by manufacturers to PBMs. The SEC filings show that the Department of Justice is also investigating payments made by PBMs to retail pharmacies or others in connection with PBM interventions." ${ }^{23}$ In late June 2003, the U.S. Department of Justice joined a whistleblower lawsuit alleging inappropriate prescription processing and dispensing practices in mail-order pharmacies owned by a PBM..$^{24}$

Another arm of the federal government has a history of skepticism of the business practices of PBMs in their relationships with pharmaceutical manufacturers. ${ }^{25}$ As noted above, the Office of Inspector General released its Compliance Program Guidelines for Pharmaceutical Manufacturers in April 2003, including guidance on "educational grants" and "payments to PBMs." ${ }^{26}$ For educational grants, even if the educational or research purpose is legitimate, the OIG states that there is risk of violation of the antikickback statue if "the manufacturer has any influence over the substance of an educational program or the presenter."27 For the latter, regarding drug manufacturer payments to PBMs, "Any rebates or other payments by drug manufacturers to PBMs that are based on, or otherwise related to, the PBM's customers' purchases potentially implicate the antikickback statute. Protection from violation of the antikickback statute is available by structuring such arrangements to fit in the GPO (group purchasing organization) 'safe harbor' at 42 CFR 1001.952 (j). That [GPO] safe harbor requires, among other things, that the payments be authorized in advance by the PBM's customer and that all amounts actually paid to the PBM on account of the customer's purchases be disclosed in writing at least annually to the customer." ${ }^{28}$ While this is a guidance and not a list of explicit demands, it is clear that customers, including the federal and state governments, will continue to seek and demand more complete disclosure of revenues and profits earned by PBMs from drug manufacturer payments, and the OIG will scrutinize professional education and grant making by pharmaceutical manufacturers to ensure that these functions are divorced from drug product sales and marketing.

In this issue of the Journal, Chung, Taira, and Noh propose an alternate paradigm for drug manufacturer payments to PBMs and health plans based upon the notion that these dollars could be better spent on measurable long-term rather than short-term outcomes or other objectives. ${ }^{29}$ While this concept may not be new, and some may argue that it is not even profound, the authors have made a useful attempt at describing the framework for such a proposal. By doing so, the authors permit managed care pharmacists to criticize details and assumptions in the 
proposal, creating the opportunity for informed and scholarly debate about alternate scenarios to the present situation. Chung, Taira, and Noh point to an example in which only $62 \%$ of 16,391 patients who received 2 COX-2 drugs were found to meet at least 1 of 6 criteria that would establish appropriate use of these drugs, as established by the health plan, and there was a significant difference between the rate of appropriateness for drug A (66.5\%) versus drug B $(56.6 \%, P<0.001)$. The authors suggest that this sort of information should be used by health plans and PBMs in making formulary placement decisions; i.e., drug A might earn placement in tier-2 copayment while drug B might be placed in formulary as tier-3 copayment or excluded from the health plan drug formulary. The manufacturers of COX-2 drugs A and B could be presented the results of periodic assessments of appropriate use, according to the criteria established by the health plan, in an effort to improve intermediate (appropriateness of use) outcomes. It is not a large leap to imagine that drug manufacturers could allocate rebate dollars for specific purposes such as the measurement and periodic reporting of key intermediate and long-term outcomes and pay-for-performance in quality measures for providers, physicians, and pharmacists. And so, we are back to the beginning, back to a fundamental concept of paying for performance of health care providers, PBMs, and other vendors that provide support to those who deliver the care to health plan beneficiaries. The data requirements, in volume and quality, for this alternate method of allocating drug manufacturer price discounts and rebates will be large.

Frederic R. Curtiss, PhD, RPh, CEBS Editor-in-Chief

\section{REFERENCES}

1. Reichert S, Simon T, Halm EA. Physicians' attitudes about prescribing and knowledge of the costs of common medications. Arch Intern Med. 2000;160(18):2799-803

2. Korn LM, Reichert S, Simon T, et al. Improving physicians' knowledge of the costs of common medications and willingness to consider costs when prescribing. J Gen Intern Med. 2003;18(1):31-37.

3. Yokoyama KK, Doan QD, Godley PJ, et al. Effect of physician profiles and academic detailing on the cost and utilization of selective serotonin reuptake inhibitors. J Managed Care Pharm. 2003;8(1):23-31.

4. United Physicians incentive program reduces pharmacy costs. PR Newswire. April 17, 2003.

5. Hoffman L, Mayzell G, Pedan A, Farrell M, Gilbert T. Evaluation of a monthly coverage maximum (drug-specific quantity limit) on the 5-HTl agonists (triptans) and dihydroergotamine nasal spray. J Managed Care Pharm. 2003;9(4):335-45.

6. Curtiss FR. Searching for drug benefit benchmarks—cost per day of therapy. J Managed Care Pharm. 2002;8(1):54-55.

7. National Institute for Health Care Management Research and Educational Foundation. Prescription drug expenditures in 2000: the upward trend continues. May 2001. Washington, DC. Available at: www.nihcm.org.

8. NIHCM. The NIHCM Foundation responds to PhRMA's criticisms of the report, "Changing Patterns of Pharmaceutical Innovation." Available at:

http://www.nihcm.org/RebuttalSAL.pdf. Accessed February 17, 2003.
9. Curtiss FR. Finding the truth about health care cost drivers-cost versus utilization factors. J Managed Care Pharm. 2003;9(3):274-75.

10. Stacy J, Shaw, E, Arledge MD, Howell-Smith D. Pharmacoeconomic modeling of prior-authorization intervention for COX-2 specific inhibitors in a 3-tier copay plan. J Managed Care Pharm. 2003;9(4):327-34.

11. Spiegel BMR, Targownik L, Dulai GS, Gralnek IM. The cost-effectiveness of cyclooxygenase-2 selective inhibitors in the management of chronic arthritis. Ann Intern Med. 2003;138(10):795-806.

12. Pear R. U.S. warns drug makers on illegal sales practices. New York Times. 2003;April 27, 2003.

13. Department of Health and Human Services Office of Inspector General. OIG Compliance Program Guidance for Pharmaceutical Manufacturers. Federal Register. 2003;68(86):23731-43.

14. Hewitt Associates. Health care expectations: future strategy and direction 2003. Available at: http://was.hewitt.com/hewitt/resource/newsroom/pressrel/2003/01-14-03.htm. Accessed March 28, 2003.

15. Cardinale V. Knotty ties—good relations with PBMs start with "full disclosure" according to health plan pharmacy director. Drug Top. January 18, 1999:52-4.

16. Examine drug plans for hidden fees. Employee Ben Plan Rev. July 1999:61. 17. Conlan MF. Eagle managed care challenged. Drug Top. October 5, 1998:85.

18. Martinez B. Rx for margins. Hired to cut costs, firms find profits in generic drugs. Wall Street Journal. March 31, 2003:A1,A6.

19. Green Sheet. January 21, 2002:3,4

20. U.S. General Accounting Office. Federal employees' health benefits: effects of using pharmacy benefit managers on health plans, enrollees, and pharmacies. GAO-03-196. January 2003. Available at: www.gao.gov.highlights/do3196high.pdf. Accessed June 16, 2003.

21. U.S. General Accounting Office. Federal employees' health benefits: effects of using pharmacy benefit managers on health plans, enrollees, and pharmacies. GAO-03-196. January 2003:28. Available at:

www.gao.gov./highlights/do3196high.pdf. Accessed June 16, 2003.

22. U.S. General Accounting Office. Federal employees' health benefits: effects of using pharmacy benefit managers on health plans, enrollees, and pharmacies. GAO-03-196. January 2003:12. Available at: www.gao.gov./highlights/do3196high.pdf. Accessed June 16, 2003.

23. U.S. General Accounting Office. Federal employees' health benefits: effects of using pharmacy benefit managers on health plans, enrollees, and pharmacies. GAO-03-196. January 2003:14, footnote a. Available at: www.gao.gov.highlights/do3196high.pdf. Accessed June 16, 2003.

24. Martinez B. U.S. is joining lawsuit that says Medco put profits before patients. Wall Street Journal. June 24, 2003:A1,A6.

25. Department of Health and Human Services Office of Inspector General. Draft OIG Compliance Program Guidance for Pharmaceutical Manufacturers. Federal Register. 2002; 67(192):62057-67.

26. Office of Inspector General. Compliance Program Guidance for Pharmaceutical Manufacturers. April 2003:20. Available at: http://oig.hhs.gov/fraud/docs/complianceguidance/042803pharmacymfgnonfr.pdf. Accessed May 8, 2003.

27. Office of Inspector General. Compliance Program Guidance for Pharmaceutical Manufacturers. Federal Register. 2003;68(86):23731-43,23735.

28. Office of Inspector General. Compliance Program Guidance for Pharmaceutical Manufacturers. Federal Register. 2003;68(86):23736.

29. Chung R, Taira D, Noh C. Alternate financial incentives in multi-tiered formulary systems to improve accountability for outcomes. J Managed Care Pharm. 2003;9(4):360-65. 